\title{
An Analysis of English Vocabulary Learning Strategies
}

\author{
Zhihong Bai \\ Shanxi Normal University, Linfen, China
}

\begin{abstract}
Vocabulary is one of the three elements of language, the building material and the basic of language. To communicate with others fluently, the first premise is that we must have a certain amount of vocabularies. Facing so many words to learn, it's necessary to investigate the vocabulary leaning strategies. The paper mainly studies the strategies of English vocabulary learning. Firstly it introduces the importance of vocabulary learning. Secondly, it explains the significance and purpose of the study, and does the survey to the current problems of students' vocabulary learning. Thirdly, it gives the definition and classification about the vocabulary learning strategies. Then, in the paper some factors which affect the strategies of vocabulary learning are listed. Finally, it points out the specific strategies of vocabulary learning and gets some opinion about it. It is hoped that this paper can offer some help for students' English vocabulary learning, and expand students' vocabulary. Also, it can improve students' interest in vocabulary learning and make vocabulary learning easy.
\end{abstract}

Index Terms-vocabulary learning strategies, English learning and teaching, learning efficiency, vocabulary learning belief

\section{INTRODUCTION}

All the words in a language make up what is generally known as its vocabulary. The term "vocabulary" is used in different senses. Not only can it refer to the total number of the words in a language, but it can stand for all the words used in a particular historical period, e.g. Old English vocabulary, Middle English vocabulary and Modern English vocabulary. We also use it to refer to all the words of a given dialect, a given book, a given discipline and the words possessed by an individual person. English is one of the world's highly developed languages. Naturally the English vocabulary is one of the largest number vocabularies in all the languages. Vocabulary learning as the foot-stone of the whole language learning, lays the foundation for students learning English vocabulary and using various English learning strategies rationally.

Language learning strategies became the main research theme in the 1970s; and vocabulary learning strategy has been the main component. Studies made by O'Malley and Chamot (1986) confirm that most language learning strategies can be used for vocabulary tasks.

Vocabulary is one of the three key factors for language learning. It is the basic to make sentences and express thoughts and meanings, and a key requirement of language communication, so a big amount of stable vocabulary is significant and essential.

\section{LITERATURE REVIEW}

Chapter two mainly introduces the importance of English vocabulary learning and describes the research situation at home and abroad.

\section{A. Importance of English Vocabulary Learning}

In the trend of globalization, internationalization of language is unavoidable. English will undoubtedly play the most important role. It includes three elements: pronunciation, vocabulary and grammar. It is obvious that vocabulary is the most essential and liveliest part of the three elements.

\section{B. The Research Situation at Home}

Since the late 1990s, Chinese scholars have studied vocabulary learning strategies, mainly through two aspects, the first is that the research results of vocabulary learning strategies are introduced from abroad; The second is that carry out research on vocabulary strategy in China. For example, Wang Chuming (1992) studied English dictation strategies through introspection and reflection. Yao Meilin, Wu Jianmin and Pang Hui (2000) investigated the English vocabulary strategy of junior three students by questionnaire and oral report. It is found that students are mainly general and mechanical, rather than specific. The level of memory strategy is not high. When students encounter complex memory tasks, they mainly choose the mechanical repetition strategy and the other strategies are complementary.

Wen Qiufang (1997) studied different learning strategies adopted by successful learners and unsuccessful learners, and then carried out comparative analysis. Liu Shaolong (2003) studied the influence of schema on listening strategy by 
means of sound thinking. Some other scholars have conducted in-depth research on foreign language vocabulary memory.

Gu Yongqi and Hu Guangwei (2003) studied students' vocabulary learning strategies and the relationship between vocabulary and English achievement through investigation. Students in the first year of college were trained for half a year, and the students' vocabulary learning strategies were understood twice by means of questionnaire survey. Students were asked to take the vocabulary test and IELTS test twice. Chen Xiaotang (2006) found that after the training of students, the types and frequency of vocabulary learning strategies are higher than before, and the relationship between vocabulary concepts and behaviors is also enhanced. The research also found that the use of different vocabulary strategies was not significantly related to the change of vocabulary and English performance.

Wang fei-fei (2016) studied the current situation of English vocabulary learning in secondary vocational schools and understood the role and potential of cooperative learning in English vocabulary teaching in secondary vocational schools. It is found that cooperative vocabulary teaching can help secondary vocational students to learn English vocabulary and improve the effect of vocabulary learning. At the same time, it is believed that some students have some negative behaviors in cooperative learning, but group cooperative learning has extensive application potential in secondary vocational schools.

\section{The Research Situation Abroad}

Foreign research on vocabulary learning strategies started in the $1960 \mathrm{~s}$, at first research focuses on the study of individual, by studying the learner's behavior to observe their effect the change of learning a language. It was later discovered that successful language learners were not necessarily positively correlated with their intelligence, but rather with their own efforts and mastery of learning strategies.

The famous linguist Wilkins comments: "Without grammar, little can be expressed; without vocabulary, nothing can be expressed"(Wilkins, 1978, p.111). Word knowledge is a necessary competence, and it is important for production and comprehension in a second language. In the importance of vocabulary in communication. He indicates, "No matter how good one's grammar is and how beautiful one's pronunciation is, but if one has no enough vocabulary to convey one's own feelings or to understand others' opinions, one still cannot communicate with others in the language". As an essential and fundamental building block of language, vocabulary learning is a key aspect of language learning, whichever curriculum or syllabus we are following and whichever model of language we are applying. The four traditional basic language skills of reading, writing, speaking and listening are all based upon the students' vocabulary knowledge.

Chamot (1986) found that successful language learners use group activity strategies more frequently to learn vocabulary. Chamot in the study found that high school English learners use in vocabulary learning strategies than heard that communication strategies used by more diverse, because vocabulary learning is the nature of the relative separation. On the other hand, the use of higher level strategies may make learners realize the importance of vocabulary. O'Malley (1986) found that students don't like to active control strategies, such as: (imagery, inference, the Key word Method), instead, they are more inclined to adopt the strategy of repetition. Learners prefer simple mechanical repetition to sophisticated strategies. The use of a higher level strategy may be the learner's awareness of the importance of vocabulary. Vocabulary learning through dictionaries is also an important learning strategy, especially for language learners at the primary stage. Besides, people who are good at using dictionaries can continue to learn outside the classroom, so they can improve their ability to learn independently.

\section{RESEARCH DESIGN}

\section{A. Research Purpose}

The current study is concerned with the question: Why do students have problems with vocabulary learning? Before we tell students what to do with their vocabulary learning, we must know what they are doing, that is to say, which vocabulary learning strategies they are using. The current study is undertaken for this purpose. The researcher tries to find the reason why students have problems with their vocabulary learning and get some information about vocabulary learning strategy in order to make some suggestions about vocabulary strategy training.

\section{B. Research Significance}

Vocabulary is the basic component of language, and a fundamentally important aspect of language development.

To students, effective learning strategies can not only maximize their vocabulary size to make learning meaningful, but also enhance students learning autonomy. Of course, it can also build up self-confidence and self-study ability.

To teachers, the result of the present study can provide teachers with problems on students' vocabulary learning. It is far better to spend time on strategies that the students can use to deal with these words than to spend time on individual words. So it is clear that if a teacher wants to help student students cope with vocabulary, particularly in their reading, they would better teach them some strategies first.

\section{Research Methods}


Using questionnaire survey of vocabulary learning strategies of the second grade non-English major students in a university to finish the quantitative empirical investigation. Through the comparison of vocabulary learning strategies of good students and poor students, it analyzes the relationship between vocabulary strategies and vocabulary scores. Finally, it makes the conclusion: for the students investigated in this study to use a wide range of strategies to learn English vocabulary, cognitive strategies were used more frequently than met cognitive and social/affective strategies.

\section{THE RESEARCH INTO SOME RELATED ISSUES}

This part will introduce some related issues. It will have a detailed review, including the definition and classification of vocabulary learning strategies.And it will illustrate some influencing Factors of Vocabulary Learning.

\section{A. Definition of Vocabulary Learning Strategies}

Definitions of vocabulary learning strategies have difference opinions. An often-quoted definition of learning strategy is given by Oxford. Learning strategies are behaviors or actions which students use to make language learning more successful, self-directed and enjoyable. In this chapter the definition from Wen Qiufang (2003) is adopted. She defined learning strategies as 'behaviors or actions which learners use to make learning more effective'. The definition stresses that the aim to use strategies is to make learning more effective; strategies are learners' behaviors or actions, not thoughts. In this way, vocabulary learning strategies can be defined as 'behaviors or actions which learners use to make vocabulary learning more effective'.

\section{B. The Classification of Vocabulary Learning Strategies}

Oxford categorizes learning strategies into two major groups: direct strategies and indirect strategies. The former refers to those strategies directly involved in the target language in the sense that they require mental processing of the language which consist of memory strategies and compensation strategies. The later refers to the strategies that provide indirect support for language learning through opportunities, controlling anxiety, increasing cooperation and other ways including met cognitive strategies, affective strategies and social strategies.

O`Malley and Chamot (1986) have carried out extensive researches providing deeper insight into learning strategies. They have analyzed learning strategies on the basis of the finding of cognitive psychology, and considered them as cognitive skills. In their framework, three major types of strategy (met, cognitive, social/affective strategies) are distinguished depending on the level or type of processing involved within the information-processing model of learning. Met cognitive strategies are higher order executive skills and used for learners to oversee, regulate, or self-direct their language learning. To be specific, Met cognitive strategies are further divided into advance organizers, directed attention, selective attention, self-management, delayed production and self-evaluation. While met cognitive strategies refer to learners' management of their learning, cognitive strategies refer to the mental processes they use to acquire, sort, remember, and use information. They operate directly on incoming information, manipulating it in ways that enhance learning. Cognitive strategies include repetition, resourcing, directed physical response, translation, grouping, note-taking, education recombination, imagery, auditory representation, key word, transfer and guessing. Social strategies are the ways in which students cooperate or interact with other people in the learning process. They include asking for the help of teacher or peers and asking for clarification. Finally, affecting strategies refer to controlling over emotions or negative thoughts in order to continue to study. The examples include self-talk and self-encouragement.

\section{The Influencing Factors of Vocabulary Learning}

There are two kinds of factors that influence the learners' vocabulary learning strategies: One is the factors of individual learners; the other is the social environmental factors.

\section{Individual Factors}

The differences between learners perform in several aspects, which include concepts, attitudes, personal emotion, and so on. The first point that the learners should pay attention to is their views about vocabulary learning. If the learner focuses on the vocabulary, they will be more use of cognitive strategies and memory strategies. If they pay attention to the function of the vocabulary, they will use fewer strategies such as cognitive, memory but more use of communicative strategies. And the age, learning motivation, character and personality differences of students and the differences of genders, also can influence vocabulary learning strategies.

\subsection{The Factor of Age}

Age is an important factor for vocabulary learning strategies. Young learners tend to rely more on specific learning tasks to use strategies. However, adult learners can use strategies neatly. Adult learning strategies are more complex than children. They always use more learning strategies.

\subsection{The Learning Motivation}

Learners' learning motivation is very important for any type of learning, including vocabulary learning. The motivation determines how much attention the learners would love to pay, how to complete a learning task and how much sense of accomplishment it will take. The researchers found that: the learning motivation has a close relationship with the use and selection of learning strategies. The learners who have strong motivation of vocabulary learning use 
more strategies than the learners who have little motivation, and different vocabulary learning motivation can affect learners choose different learning strategies. In foreign vocabulary learning strategies teaching, if the learners ignore their learning motivation, then it will lead to the failure of the strategies in teaching. Therefore, in the strategies teaching, teachers should understand the learning motivation of the learners and encourage their enthusiasm to learn vocabulary. In turn, using the corresponding learning strategies can improve the learners to complete initiatively the vocabulary learning tasks. Learning motivation means something which can push students to learn directly in an internal power. Learning motivation is a complex psychological activity. As a way to stimulate and guide students' learning, it plays an important role on students' learning. It is important for learners to behave and act that it determines the enthusiasm, tendency, selection and consciousness of individual activities.

\subsection{The Personality Difference Among Students}

Every student is an individual having their own living and growth environment, which formed a unique personality and individual differences. It also changes the different people's interests and needs. A research shows that most of the teachers and learners believe the personality factor plays an important role in foreign language learning. The different personality of students will have different degrees of influence on the English vocabulary learning. The researchers also found that some personality traits are related to the learner's strategies choice. Some researchers have proposed assumptions regarding the relationship between the usage of strategies and one's personality. They point out each character have the tendency of using some learning strategies. For example, Researchers widely believe that extroverted learners will use more emotional and visual strategies. Some others think that learners of emotional type use more vocabulary learning strategies than thinking type. Although these primary research conclusion needs to be further confirmed, the influence of learners' personality characteristics on their learning strategies and the teaching can't be ignored.

\subsection{The Differences of Gender}

Gender differences are brought to the attention of the researchers increasingly in vocabulary learning. Research shows that gender differences will lead to male learners and female learners use different vocabulary learning strategies. They reported that Female learners use more social strategies and more frequently than male learners. Oxford found that although a lot of women learners use learning strategies more frequently than men learners, after strategy training, the male learners will show considerable advantages in the strategy usage. However, so far in the teaching and research of the strategies, the gender differences have been paid little attention. If researchers and teachers can consider gender factors in the teaching strategies, and distinguish male from female, then they can achieve a better teaching effect in the strategies.

\section{The Factors of Social Environmental}

As a language is a social phenomenon in human communication, it is close related to the society, so the using of learning strategies in vocabulary learning is restricted by social environment. Thus, the social environment, to a great extent, affects the learner's strategies. This will be bound to affect the learners' mentality and the use of learning strategies indirectly.

\section{The ANalysis OF ENGLISH VocabUlary LEARNING StRategieS}

This chapter provides a detail presentation about the strategies of vocabulary learning. It summaries the belief about vocabulary learning and overall pattern of the use of strategies.

\section{A. Vocabulary Learning Belief}

Wen Qiufang believes that English learning system includes two systems, beliefs and methods. Students' beliefs are important determinants of their behaviors. Vocabulary learning belief refers to the learner's attitude toward vocabulary learning. It has great effects on student choice and use of the strategies and will help the students control their learning process and make an evaluation for their learning outcomes. Therefore, the researcher will understand better the students' use of strategies by investigating students' vocabulary learning beliefs. They predominantly believed that word should be carefully studied and put to use. Their results proved that students like to use function-focused belief. The students who hold this belief preferred to learn English by using it.

It was consistent with some western researcher. For example, Krashen and Parry didn't encourage English students to recite the vocabulary, and they held that vocabulary should be learned through extensive reading. Extensive research has demonstrated that vocabulary is easier to learn in context than in isolated word lists because the meaningful context permits more complex and deeper processing. The students began to realize that using the language was an effective way to learn a foreign language. They found out that it was easy for them to remember a new word by using it. The new words could be learned easily by using either in the daily life or in written way. Learning vocabulary by using them is much easier to them than by just reciting it mechanically.

\section{B. Overall Pattern of English Vocabulary Learning Strategies}

Factor analysis on English vocabulary learning strategies items identified 16 factors for learners' English vocabulary learning strategies. The 16 factors are: self-management, plan-making\& plan-implementing, selective attention, learner autonomy, reviewing\& testing, repetition, association, imagery, word formation, grouping, contextualization, dictionary 
use, note-taking, guessing, affective control and social activities. O'Malley\& Chamot (1986) distinguish three general types of learning strategies: met cognitive strategies, cognitive strategies and social/affective strategies. This classification of learning strategies is well recognized by scholars and researchers. According to the factor analysis, the 16 factors are further classified into met cognitive strategy, cognitive strategy and social/affective strategy.

In this part, we will try to find out the overall feature of the subjects' vocabulary learning strategies use at met cognitive, cognitive and social affective levels respectively. Among the three types of vocabulary learning strategies, the cognitive strategy is the most frequently used, and the met-cognitive strategy followed. The social/affective strategy used the lowest.

\section{The Use of Met Cognitive Strategies}

The selective attention belongs to met cognitive strategies. Most students pay more attention to those words that are considered or reminded as frequently used-words. The reason why the selective attention is used highest is the students often selectively pay attention to some words or types of word knowledge. This can be traced to the teaching methods adopted by most English teachers. In their teaching practice, they tend to select some basic important words and provide detailed explanations to the students. While teaching these words, they tend to put emphasis on various aspects of word knowledge, such as multiple meanings, grammatical features, collocations and so on.

The met cognitive vocabulary learning strategies are used for study. The autonomy strategies are used lowest in met cognitive through the observation for students. Many students buy some vocabulary books to learn and remember a lot from vocabulary books. Only a few subjects read English newspaper or magazines to enhance the knowledge of the vocabulary. Much fewer of the students make word cards in order to review and memorize words at any free time. This shows that most of the subjects lack autonomy in learning vocabulary. According to the interview, some students still regard teacher's instruction in class and the textbooks they use as the main sources in their English learning. They have been accustomed to leaning English in this way. They may not realize the importance of learner autonomy. When the students were in middle school, they got used to the instructions of the teachers. After they came into the college, they could not adapt to the teaching and learning methods of college quickly. They may still have not completely formed the habit of autonomous learning. Meanwhile, it was found that they learned new words mostly from vocabulary books rather than reading materials, such as English newspapers and magazines. Students held the belief that vocabulary was learned by memorization, that is to say, vocabulary was learned intentionally, not incidentally acquired in reading or other sources. Vocabulary books were a more direct source for vocabulary learning. Wang (1998) explains that firstly Chinese learners are inevitably influenced by language learning traditions in Chinese, which put emphasis on intentional memorization of words. Secondly, Chinese English learners have only limited access to English input due to the restriction of learning situations. Therefore, memorizing words in the vocabulary books was considered as a more effective way to learn new words.

\section{The Use of Cognitive Strategies}

The cognitive strategies are most frequently used. Dictionary use strategy belongs to one of cognitive strategies. It is the highest frequently used one. Most of the subjects often consult dictionary. Many students pay attention to phrases or set expressions that go with the word they look up. Most of the subjects not only look up new words they encounter for meaning but also look up some learnt words for more accurate usage or confirm the knowledge about them. When looking up a word, fewer of the students pay attention to its English explanation as well as its Chinese explanation. The dictionary use strategy is popular among the subjects. The results show that a bilingual dictionary is most popular. The present research had a similar finding with it. The subjects often validate or identify the necessary meaning of consulted words or increase other knowledge of learned words through dictionary use. They are relatively mature dictionary users. The subjects may think that learning vocabulary in the dictionary is the most efficient and immediate way. They could find very clear usages of a new word, useful expression and fixed phrases of the word, the sentences with that word and even a picture of a word in the dictionary. They lack the actual communication environment to learn vocabulary. If they have no chance to learn the words naturally and communicate with native speakers, they will solve problems by looking up the dictionaries.

The guessing strategy also belongs to cognitive strategy. Many of the subjects guess the word meanings by word formation. Most of the subjects guess the word meanings by the context. Fewer of the subjects guess the word meanings by the background information. It is impossible for students to know all the words in the process of reading, if they keep consulting a dictionary when they come across new words, which takes them a considerable amount of time. In addition, most students are field-independent. They prefer to learn independently rather than cooperate with others. As a result, they may choose to solve the problems by guessing the meaning of an unknown word. If the guessing strategy is not working or they want to make sure the exact meaning, they may consult a dictionary, and guess the meaning of a word by their word formation, parts of speech, and the structure of the sentences and the context of the passage. Only some of the subjects guess the words by background information. There is a lot of background information related to the western culture, customs and history. As the subjects are not English majors, they lack the knowledge about background information. It is difficult for them to use the guessing strategy very well.

Then the cognitive strategies also includes note-taking. Many students make a note of the useful expression or phrases related to a word. Fewer of the subjects take down the meaning and other knowledge of commonly used words they encounter out of class. The results show that note-taking strategies are favored by most of the students. The 
subjects write down not only the Chinese equivalents, the simple surface knowledge, but also some useful expressions, phrases and sample sentences. They can use the note-taking strategies well. Compared to the habit of taking note in class, fewer subjects take notes out of class. But there are still more than half students to take notes when they encounter some words out of class. This may be influenced by the Chinese educational system for a long time. In middle school, teachers would like to encourage the students to take notes in the class. The habit was trained for a long time. When the students go to college schools, they still have such a good habit. It could help students to have a deeper impression of the new words and remember them. Knowledge would be systematic by taking notes. The strategy should be encouraged to use.

\section{The Use of Social/Affective Strategies}

Most of the subjects can concentrate on vocabulary study. Fewer of them reported that when vocabulary-learning outcomes were not satisfactory, they would encourage themselves in their studies. As we know, learners have more awareness about developing self-confidence, self-encouragement, and reducing anxiety when they encounter difficulties. This may be due to the influence of the Chinese culture, too. The students have been educated to control themselves ever since they were very young. In contrast, only a few students go to English corner and use as many newly learnt words as possible. Fewer seek and never miss any opportunity to converse with foreigners in English.

Learners seldom sought opportunities to practice and acquire English vocabulary through English communicative activities. Most learners prefer to learn independently rather than cooperate with their classmates, native speakers or other people. Most Chinese students are shy. They dare not open mouths to speak English in front of others.

\section{CONCLUSION}

Vocabulary learning not only refers to mastering a certain number of words or phrases, but also includes the ability to use vocabulary correctly. Therefore, correct vocabulary learning strategies are very important to students. Of course there are also some other books or issues on vocabulary learning, especially vocabulary memorizing. Vocabulary is the key of language learning. Each language learner should try to find one or some proper ways that suit for him to enlarge their vocabulary and improve their English learning. Every kind of vocabulary learning method is very useful and valuable. Language learner should also know these methods' advantages and disadvantages and make full use of them according to their own situation and the different tasks. And they have to choose different strategies. Vocabulary learning is a long-term task, correct vocabulary learning strategies enable students to learn vocabulary effectively independently of their teachers, and vocabulary is constantly changing and expanding, and correct vocabulary learning strategies can enable learners to learn vocabulary effectively at any time.

What's more, if the vocabulary is limited, the learner's scope of thought will be narrow and they will face many difficulties in communication. Therefore, they must know that they will not succeed if you do not work hard. The most important thing that everyone should remember is that study hard is the base of success. Regardless of which strategies the students use to learn vocabulary. As long as it is helpful to the learning of vocabulary, and improving students' English level, that is a good way.

English vocabulary learning strategy is helpful to improve the efficiency of vocabulary learning, but not all strategies are adapted to each individual. Teachers should choose teaching strategies according to different situations of learners in order to train learners to choose effective learning strategies independently, and meet students' learning needs according to their different levels and needs, and start with the weak links, focus on them, and drive the improvement of other abilities.

\section{REFERENCES}

[1] Chamot, A.U. \& O’Malley, J.M. (1986). A Cognitive Academic Language Learning Approach. National Clearinghouse for Bilingual Education, 2, 88-92.

[2] Chen Xiaotang. (2006). English Vocabulary Learning Strategies. Shandong: Shandong University Press.

[3] Gu Yongqi, Hu Guangwei. (2003). Empirical Study on English Learning Strategies. Xi'an: Shaanxi normal University Press.

[4] Liu Shaolong. (2003). On the Acquisition and Development of Second Language Vocabulary. Foreign language Teaching, 2,102-105.

[5] Wang Chuming. (1992). A Survey of Chinese students' Foreign language Learning Styles. Changsha: Hunan Education Press.

[6] Wang Feifei. (2016). The Application of Cooperative Learning in Vocabulary Teaching in Secondary Vocational Schools. Shandong normal University. 3, 11-14.

[7] Wang Wenyu. (1998). Concepts, Strategies and English Vocabulary Memory. Foreign Language Teaching and Research. 1,47-52.

[8] Wen Qiufang. (1997). Study of English Learning Strategy Theory. Xian: Shaanxi Normal University press.

[9] Wen Qiufang. (2003). The Road to Success in English Learning. Shanghai: Shanghai Foreign language Education Press.

[10] Wilkins, D. A. (1978). Linguistics in Language Teaching. Massachusetts: The MIT Press.

[11] Yao Meilin, Wu Jianmin, Pang Hui. (2000). English Vocabulary Memory Strategies of Junior High School Students. Psychological Science, 5, 26-30. 
Zhihong Bai was born in Lvliang, China in 1993. She is studying for her Master's degree in linguistics in Shanxi Normal University, China.

She is currently a student in the school of Shanxi Normal University. Her research interests include translation and applied linguistics. 